\title{
On a new method of distinguishing the protoxide of iron from the peroxide by the blowpipe
}

\section{E.J. Chapman Esq}

To cite this article: E.J. Chapman Esq (1848) On a new method of distinguishing the protoxide of iron from the peroxide by the blowpipe, Philosophical Magazine Series 3, 32:215, 309-310, DOI: $10.1080 / 14786444808645984$

To link to this article: http://dx.doi.org/10.1080/14786444808645984

曲 Published online: 30 Apr 2009.

Submit your article to this journal $\sqsubset$

Џll Article views: 2

Q View related articles $\square$ 
inclined to think I had over-estimated its dimensions. Probably a fifteenth part of the solar diameter would be nearer the truth. The obscuration was however so large as to attract the notice of the most unobservant. People in Prince's Street, I understand, were gazing at it as they lounged along. Having no pretension myself to astronomical acquirements, I can claim only to be considered as a simple eye-witness to a fact, and shall be glad if chance has led me to corroborate the observations of Sir J. W. Lubbock or others. The latter gentleman, in his Note on Shooting Stars, also mentions having recently seen other solar spots with the naked eye, which disappeared altogether in a day or two. This I had read before receiving: his obliging communication. The natural inference from similar repeated observations $I$ imagine must be, that the great forces in operation on the solar surface are gradually increasing and extending their energies; so that we may possibly have, in process of time, half of the sun's body obscured, as Abulferagius relates occurred in the seventeenth year of the emperor Heraclius during the space of nine months! The solution of this mighty solar problem is yet to be achieved; and perhaps it would be a step to our knowledge of the physical constitution of the sun, if by calculating the perturbations of some comet, as suggested by Sir J. W. Lubbock, its crigin could be traced back to the solar mass, from which it had been projected by the tremendous forces there in obvious operation.

I am, Gentlemen, Your very obedient Servant,

Edinburgh, March 11, 1848. W. Pringle.

\section{ON A NEW METHOD OF DISTINGUISHING, THE PROTOXIDE OF IRON FROM THE PEROXIDE BY THE BLOWPIPE. BY E. J. CHAPMAN, EsQ.}

The presence of iron in any compound may be detected, it is well known, and with great certainty, by the blowpipe; but no method has hitherto been given by which the protoxide of iron can bc distinguished from the peroxide by means of that instrument. After several trials to accomplish this, I discovered the following inethod, which is both decisive and simple, requiring rooreover for its performance but the ordinary reagents of the blowpipe-case.

A very minute quantity of oxide of copper is to be dissolved in a bead of borax on the platinum wire until the glass be faintly coloured; and the substance under examination being added to it, the whole is to be subjected, but for an instant only, to a reducing flame; when, if protoxide of iron were originally present in the assaymatter, the $\mathrm{CuO}$ will be reduced to $\mathrm{Cu}^{2} \mathrm{O}$, forming small red spots or streaks, which become visible as the glass cools. The $\mathrm{FeO}$ is converted into $\mathrm{Fe}^{2} \mathrm{O}^{3}$ at the expense of the oxygen of the copper.

In the above experiment, if the glass were exposed for too long a time, the oxide of copper might become reduced, even if the substance under examination contained only the peroxide of iron, as 
this would be converted by the flame into protoxide, and thus act, as before stated, on the oxide of copper; and if, furthermore, this latter substance were contained in too large a quantity in the borax glass, it might become reduced by the sole action of the yellow flame, and thus give rise to an erroneous result. To obviate, therefore, all doubt as to the presence or absence of $\mathrm{FeO}$ in any compound, I find it advisable to couduct the operation in a different manner, by which not the slightest uncertainty can be experienced.

The borax bead must be coloured by a sufficient quantity of oxide of copper to render it of a fine blue tint, but transparent, when cold. To this the substance under examination in powder must be added, and the bead exposed for a moment, or until the iron compound begins to dissolve, to an oxidating flame. If peroxide of iron alone be present, the glass will remain transparent, and of a green or bluish-green colour; but, on the contrary, if the added substance contained protoxide of iron, the glass on cooling will be marked with opake red patches, due to the reduction of the $\mathrm{CuO}$ to $\mathrm{Cu}^{2} \mathrm{O}$, as before explained. Care must be taken not to continue the blast too long, otherwise the suboxide of copper might be again oxidized, and the whole of the protoxide of iron converted into peroxide. After one or two trials, however, no error can possibly arise.

This reaction is not prevented by the presence of silica or other acids. Amongst the silicates, the hedenbergite (a variety of augite) $3 \mathrm{CaO}, 2 \mathrm{SiO}^{3}+3 \mathrm{FeO}, 2 \mathrm{SiO}^{3}$, the dark-coloured hornblendes $\left.\begin{array}{l}\mathrm{CaO} \\ \mathrm{MgO}\end{array}\right\} \mathrm{SiO}^{s}+3 \mathrm{FeO}, 2 \mathrm{SiO}^{s}$, lievrite $3\left({ }^{3} \mathrm{CaO}^{\mathrm{FeO}} \mathrm{SiO}^{s}\right)+2\left(\mathrm{Fe}^{2} \mathrm{O}^{s}, \mathrm{SiO}^{3}\right)$, and other minerals, give very positive results.

Finally, it will be perceived that in certain cases the protoxide of iron, either alone or in combination as a salt, may serve to replace tin in the detection of oxide of copper by the blowpipe. For instance, when testing for minute portious of copper with borax on the platinum wire, the glass must be removed to a piece of charcoal if we wish to render evident the red suboxide by means of tin; for otherwise the end of the wire would be destroyed, the lin forming with it a fusible alloy. By employing, however, a small fragment of sulphate of iron to ensure this reduction, the bead may still be retained on the platinum wire; and we shall thus effect a saving of time and trouble, and preserve our charcoal for other experiments, an advantage of no little consequence when travelling, or in situations where good charcoal is not easily procurable. Nevertheless, it must be confessed, that, under other circumstances, tin is, for this purpose, the better reagent of the two.-From the Chemical Gazette for March 1, 1848 .

\section{ON THE EXISTENCE OF SEVERAL METALS IN THE HUMAN BLOOD, AND THE FIXED SALTS IT CONTAINS.}

M. Millon states, that when blood flowing from a vein is received into about three times its bulk of water, and after this dilution is 